\title{
O CAMINHO DA PARTICIPAÇÃO POPULAR PARA A CONSOLIDAÇÃO DA DEMOCRACIA
}

Cícera Amanda Guilherme Fernandes

Ramiro Ferreira de Freitas

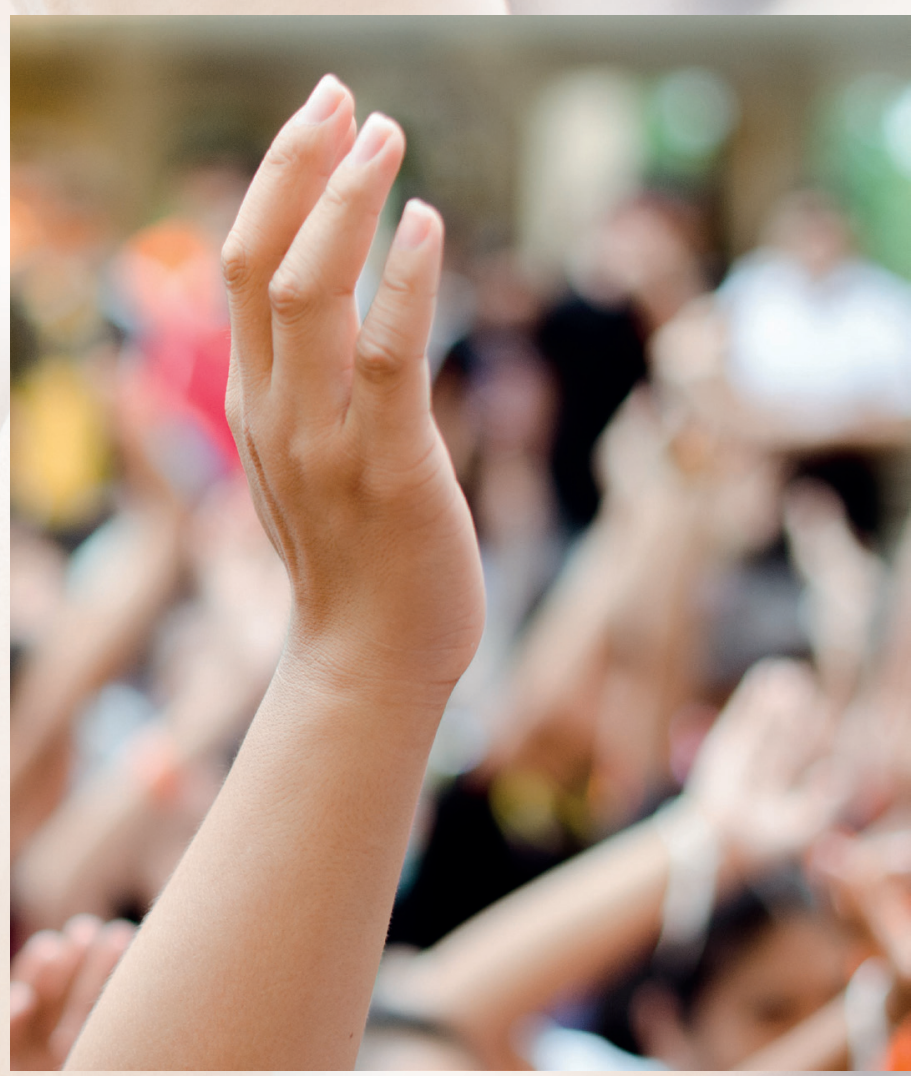





\title{
O CAMINHO DA PARTICIPAÇÃO POPULAR PARA A CONSOLIDAÇÃO DA DEMOCRACIA
}

\author{
Cícera Amanda Guilherme Fernandes \\ Ramiro Ferreira de Freitas \\ Universidade Regional do Cariri (URCA), Crato-CE, Brasil
}

\section{Resumo}

Com o propósito de realizar uma análise breve sobre a participação popular e os caminhos para chegar ao seu exercício pleno, este artigo faz indagações e constatações a respeito da importância da participação popular para a garantia do modelo democrático. Utiliza-se a metodologia dedutiva e uma análise histórico-crítica para entender os aspectos mais relevantes do tema. Em entremeios, revela-se a crise de representatividade por que passa a democracia, com todas as mazelas que tem enfrentado nos seus primeiros anos de reimplantação, tendo em vista que quase todos os países latino-americanos saíram recentemente de regimes ditatoriais de governo. Nessa associação entre a participação popular e a continuidade da democracia, na qual aquela é inerente a esta, é que se pode construir uma sociedade verdadeiramente igualitária, na qual os cidadãos possam conhecer os seus direitos e deveres para desfrutá-los e exercê-los com responsabilidade. Para que a sociedade alcance esse nível de comprometimento é imprescindível a educação cidadã, que é a capacitação do povo para atuar ativamente nos momentos de debate de ideias e decisões que representam os seus interesses e o interesse comum. Em conclusão, percebe-se que um dos elementos fundadores da democracia é a participação popular, a soberania nascida do povo, que, junto com a dignidade da pessoa humana, são as bases deste regime de governo. Tais princípios devem ser protegidos e efetivados para que a democracia se firme e não sofra percalços ou sobressaltos.

Palavras-chave: participação popular, crise de representatividade, educação cidadã.

Os autores: Cícera Amanda Guilherme Fernandes é professora assistente da Universidade Regional do Cariri, no Curso de Direito. Ministra cursos preparatórios para concursos públicos. Pesquisa as áreas da Sociologia Jurídica e Direito Constitucional. Coordena o curso de pós-graduação em Direito Constitucional — URCA. Mestre em Direitos Sociais e Políticas Públicas pela UNISC-RS. Especialista em Direitos Humanos Fundamentais — URCA-CE.

Ramiro Ferreira de Freitas é advogado (OAB-CE) e pós-graduando em Direito das Famílias e em Direito Constitucional pela URCA (Universidade Regional do Cariri), graduado em Direito pela mesma instituição.

Recebido: 26 de Novembro de 2017; avaliado: 8 de Fevereiro de 2018; aceito: 3 de Janeiro de 2018. 


\title{
THE PATH OF POPULAR PARTICIPATION FOR THE CONSOLIDATION OF DEMOCRACY
}

\author{
Cícera Amanda Guilherme Fernandes \\ Ramiro Ferreira de Freitas \\ Universidade Regional do Cariri (URCA), Crato-CE, Brasil
}

\begin{abstract}
Aiming to make a brief analysis of popular participation and the ways to reach its full application, this article presents inquiries and findings about the importance of popular participation to ensure the democratic model. It uses a deductive methodology and a historical-critical analysis to understand the most relevant aspects of the subject. In addition, it illustrates the crisis of representation faced by democracy, with all the difficulties it had to combat in its early years of reestablishment, considering that almost all of the Latin American countries have come out of dictatorial government regimes in recent years. It is this alliance between popular participation and the continuity of democracy, where the first is inherent to the last, that allows building a truly egalitarian society, where citizens can know their rights and duties, as well as enjoy and practice them with responsibility. For society to reach this level of commitment, citizen education is essential, as well as the training of people to participate actively in debates of ideas and decisions that correspond to their interests and to common interest. In conclusion, it is perceived that one of the founding elements of democracy is popular participation, sovereignty that comes from the people, which, together with the dignity of the human being, is the basis of this governmental regime. Such principles must be protected and applied in order to consolidate democracy.
\end{abstract}

Keywords: Popular participation, crisis of representation, citizen education.

The authors: Cícera Amanda Guilherme Fernandes is an Assistant Professor in Law at the Universidade Regional do Cariri (URCA). She teaches preparatory courses for public competitions. Her research areas include Legal Sociology and Constitutional Law. She coordinates the postgraduate course in Constitutional Law at the URCA. She has an MA in Social Rights and Public Policies from the Universidade de Santa Cruz do Sul (UNISC-RS). She is a specialist in Fundamental Human Rights (URCA-CE).

Ramiro Ferreira de Freitas is a lawyer (OAB-CE) and graduate student in Family Law and Constitutional Law at the Universidade Regional do Cariri (URCA). He has a law degree from the same IES.

Received: November 26, 2017; evaluated: February 8, 2018; accepted: January 3, 2018. 


\title{
EL CAMINO DE LA PARTICIPACIÓN POPULAR PARA LA CONSOLIDACIÓN DE LA DEMOCRACIA
}

\author{
Cícera Amanda Guilherme Fernandes \\ Ramiro Ferreira de Freitas \\ Universidade Regional do Cariri (URCA), Crato-CE, Brasil
}

\section{Resumen}

Con el propósito de realizar un análisis breve sobre la participación popular y los caminos para llegar a su ejercicio pleno, este artículo hace indagaciones y constataciones al respecto de la importancia de la participación popular para la garantía del modelo democrático. Se utiliza el presente artículo de la metodología deductiva y de un análisis histórico-crítico para entender los aspectos más relevantes del tema. Además de esto, revela la crisis de representatividad por la que pasa la democracia, con todas las dificultades que se ha enfrentado en sus primeros años de reimplantación, teniendo en cuenta que casi todos los países latinoamericanos han salido, recientemente, de regímenes dictatoriales de gobierno. En esa asociación entre la participación popular y la continuidad de la democracia, donde aquella es inherente a esta, es que se puede construir una sociedad verdaderamente igualitaria, donde los ciudadanos puedan conocer sus derechos y deberes, disfrutarlos y ejercerlos con responsabilidad. Para que la sociedad alcance ese nivel de comprometimiento es imprescindible la educación ciudadana, la capacitación del pueblo para actuar activamente de los momentos de debates de ideas y decisiones en lo que dice respecto a su interés, al interés común. En conclusión, se percibe que uno de los elementos fundadores de la democracia es la participación popular, la soberanía nacida del pueblo, que, junto a la dignidad de la persona humana, son las bases de este régimen de gobierno. Tales principios deben ser protegidos y realizados para que la democracia se establezca y no sufra contratiempos o sobresaltos.

Palabras clave: participación popular, crisis de representatividad, educación ciudadana-

Los autores: Cícera Amanda Guilherme Fernandes es profesora asistente de la Universidade Regional do Cariri, en el Curso de Derecho. Ministra cursos preparatorios para concursos públicos. Investiga las áreas de la Sociología Jurídica y Derecho Constitucional. Coordina el curso de posgrado en Derecho Constitucional — URCA. Máster en Derechos Sociales y políticas públicas de la UNISC-RS. Especialista en Derechos Humanos Fundamentales - URCA-CE.

Ramiro Ferreira de Freitas es abogado (OAB-CE) y estudiante del posgrado en Derecho de las Familias y en Derecho Constitucional de la URCA (Universidade Regional do Cariri), graduado en Derecho de la misma IES.

Recibido: 26 de noviembre de 2017; evaluado: 8 de febrero de 2018; aceptado: 3 de enero de 2018 . 


\section{Considerações prévias}

Em um momento de profunda crise de reconhecimento da legitimidade dos modelos representativos, a construção de conhecimento e discussão em torno da participação popular torna-se mais que salutar, faz-se imprescindível.

Debater e informar a respeito do que é a cidadania, de como deve ser exercida, de quais instrumentos já se dispõe legalmente - por previsão constitucional - e do exercício de uma cidadania ativa e participativa é fundamental para a continuidade do processo de democratização pelo qual passa boa parte dos países latino-americanos, entre eles o Brasil.

Há uma associação intrínseca entre a participação popular e a democratização das relações entre o Estado e a sociedade, em que só será possível entender um verdadeiro processo democrático quando essa sociedade for composta por indivíduos capazes e sabedores da necessidade de atuar em prol dos interesses comuns, conscientes do seu papel de cidadão.

$\mathrm{Na}$ América Latina, a chamada redemocratização, na qual os Estados tentam se reorganizar em modelos mais abertos, através da proclamação das Constituições promulgadas como Estados democráticos de direito, teve início a partir dos movimentos contrários aos regimes ditatoriais que, na segunda metade do século passado, sobretudo durante as décadas de 1960, 1970 e 1980, estiveram em vigência nessa região por um lapso temporal relativamente longo (com breves espaços democráticos ou, em casos mais extremos, fechamento total e negação às liberdades individuais). Os impactos do autoritarismo permanecem vivos na memória e no sentido das construções identitárias que são "subvertidas", nos países do Sul, tradicionalmente colonizados — "nuestra tierra" —, por forças elitistas nacionais e internacionais.

Muito significou traduzir para os documentos magnos a proposição de um regime democrático de governo. Tais declarações impuseram obediência ao princípio da liberdade de expressão e ao pluralismo ideológico e político, derrubaram os, outrora intransponíveis, muros da censura, aclararam as atividades da administração pública e reavivaram o poder da lei em defesa da dignidade da vida humana. Claras conquistas se forem vislumbradas em uma perspectiva retrógrada e analisadas em comparação ao modelo antes aplicado. 
Convém que não se esqueça do passado. Convém que os fatos sejam analisados sempre no seu panorama histórico, a fim de que não se desconheça o sentido evolutivo ou involutivo que receberam ao longo do tempo.

Hoje, entende-se que o processo de redemocratização, embora tenha manifestado evolução, necessita ser apurado e seguir a incessante marcha das transformações sociais.

As estruturas sociais receberam novos formatos, desde a redemocratização, o processo de globalização acelerou-se e as novas tecnologias de acesso à informação causaram uma verdadeira revolução na vida em sociedade.

Transformar o indivíduo, cidadão passivo e conformado com as benesses do Estado, em um cidadão atuante, que conhece os direitos já alcançados e sabe como exercê-los e, caso sejam tolhidos, defendê-los ou resgatá-los de ameaças é um passo imprescindível para a renovação da democracia e a sua plena concretização.

Há que se engendrar um pensamento comum de defesa da democracia e de garantia da efetivação das conquistas alcançadas a custo de vidas. É necessário perscrutar os passos que levem à conscientização de todos sobre a importância de estar a par de todas as decisões políticas e, dessa forma, descobrir caminhos para a participação popular.

\section{Caminhos para a participação popular}

Educar para a cidadania. Isso implica em introduzir nos currículos escolares noções de Direito Constitucional — com ênfase no estudo dos Direitos Humanos e Fundamentais - implantar mecanismos de participação, já previstos na norma constitucional, nos diversos poderes e setores da administração pública e estimular a ampliação da participação direta nos cargos eletivos, através de uma reforma do processo eleitoral, em que haja transparência sobre as campanhas e o financiamento queé recebido em prol das candidaturas. Esses elementos podem ser de fundamental importância para a transformação social exigida para a efetividade da democracia, com a conquista da cidadania ativa.

Há sinais de urgência por tais mudanças, como, por exemplo, o descrédito nas instituições - em boa parte devido à sua incapacidade em gerir os conflitos e administrar os bens e serviços públicos - e a incredulidade na existência de 
probidade dentro da máquina administrativa em quaisquer dos Poderes, que são fatores que recrudescem à medida que mais se conhece e investiga os desmandos e as variadas formas e práticas de atos de corrupção, que existem desde a época do Brasil Colônia e foram sendo aperfeiçoadas ao longo das décadas, até o século presente.

Outro vetor de comprovação deste momento transitório e desta revisão paradigmática é a crise de representatividade pela qual passa o nosso sistema político. Crise esta que pode funcionar como um fator que impulsione as transformações esperadas.

Leal, em um estudo conceitual sobre a democracia contemporânea, infere que:

De qualquer sorte, mesmo com tal instrumentação formal e material do fenômeno político, dirigido à gestão social das demandas sociais, revela-se inexorável a percepção de uma crise da representação política que vai denunciando a fragilidade dos instrumentos e mecanismos referidos, principalmente no âmbito da representatividade, colocando em xeque as próprias instituições clássicas da democracia liberal burguesa (Parlamento, Partidos Políticos, Poder Judiciário, Executivo etc.). Daqui, em razão também da complexidade da sociedade industrial, outro modelo de democracia vai se estabelecendo no cenário do século XX: a possibilidade de uma democracia mais participativa. ${ }^{1}$

Nas passeatas e manifestações, ocorridas em junho de 2013, iniciadas em protesto pelo aumento de tarifas de passagens dos transportes públicos nas capitais e que se espalharam por quase todo o país, um dos mais repetidos dizeres em faixas e cartazes era: "não me representa". Embora esses movimentos tenham sido muito criticados, principalmente por seu caráter incógnito ou exageradamente múltiplo em relação ao fundamento das reivindicações, eles evidenciaram a capacidade de indignação frente a situações críticas e de respostas comunitárias, ainda que descoordenadas, ao poder instituído, quando este não revela, em seus atos e comandos, o interesse público.

Sobre esse descrédito no sistema representativo, principalmente em termos de casas legislativas, alguns autores citam até as expressões "vazio de diálogos" e "vácuos de diálogos" para referir-se às dissonâncias retóricas quanto ao que se ouve de clamor

1 Rogério Gesta Leal, Teoria do Estado. Cidadania e poder político na modernidade (Porto Alegre: Livraria do Advogado, 2001), 199 
social em relação ao produzido em termos de legislação. É relevante dizer que o problema se estende para além das fronteiras nacionais, como bem cita Eduardo Luchesi:

Todavia, a representatividade dá sinais de cansaço não só em solo pátrio, mas também em terras alienígenas, onde a vontade da população é dissonante da preconizada nas casas legislativas, criando vácuos de diálogo entre os dois grupos que deveriam, num primeiro passo, caminhar em conjunto. Por isso, a arte deliberativa e participativa ganha força e serve de alento por tentar conjugar dois grupos antagônicos, irmanando-os novamente em torno do nascedouro de normas legais através do debate ou mesmo da teoria discursiva, tanto asseverada por Habermas. ${ }^{2}$

Pensar a participação popular a partir desse viés, como um espaço de interseção entre o representado e o representante, onde aquele pode fazer-se ouvir e ter voz ativa nas decisões, com o cuidado de que elas tenham consonância com os anseios sociais, constitui um passo no caminho para alcançá-la em sua plenitude. Não considerá-la um momento apenas, como espectro da história. Pensá-la, idealmente, como um elemento constante e formador da estrutura democrática.

Há um uso retórico do termo participação popular/participação social como sinônimo de democracia, controle social ou parceria, conforme nos alerta Carvalho ${ }^{3}$, que deve ser evitado. No texto de Santos Jr., "participar politicamente significa, fundamentalmente, tomar parte nas decisões sobre políticas públicas. Consiste em formar opinião sobre uma decisão do Estado; em expressar, pública e livremente, essa opinião, em vê-la levada em consideração".

A democracia, para ser legítima e efetiva, exige a presença da participação popular como um de seus elementos basilares, esse elemento é o formador da soberania popular, ele e a dignidade da pessoa humana são citados como pilares do regime democrático de governo.

2 Eduardo Luchesi, "Participação política para humanização do processo legislativo e garantia da máxima efetivação dos direitos humanos" em Constitucionalismo contemporâneo: desafios e perspectiva. Org. Clovis Gorgzevski e Mônia Clarissa Henning Leal (Curitiba: Multideia, 2012), 159.

3 Maria do Carmo A. A. Carvalho, Participação social no Brasil hoje, (São Paulo: Instituto Pólis, 1998), http:// polis.org.br/publicacoes/participacao-social-no-brasil-hoje/.

4 O. A. Santos Jr., "Dilemas e desafios da governança democrática" em: Os sentidos da democracia e participação, org. Ana Claudia Chaves Teixeira (São Paulo: Instituto Pólis, 2005), 41-46. 
O duplo alicerce estabelecido pela Constituição brasileira em 1988, soberania popular e dignidade da pessoa humana, serve de embasamento à democracia, esses dois princípios devem ser, além de protegidos, efetivados.

Bonavides ${ }^{5}$ inclui ainda os princípios da soberania nacional e da unidade da Constituição como cardeais para a construção da estrutura constitucional da democracia participativa.

Preocupado com a conjuntura que medeia a crise das representações, ele escreve sobre o princípio da soberania popular:

Atribui-se, por conseguinte, neste livro, extrema importância à defesa e salvaguarda do mais ameaçado e comprometido dos princípios que organizam a vida nacional e preservam nossa identidade democrática, a saber, o princípio da soberania popular — de último, nas duas casas do Congresso Nacional, tão desfigurado, tão atraiçoado, tão ferido pela covardia dos quadros representativos, os quais, em aliança com o Executivo, consentem que este leve a cabo a tarefa de despedaçar a Constituição e as leis. ${ }^{6}$

O autor eleva o princípio da soberania popular a um papel de responsável pela continuidade das conquistas alçadas em respeito à democracia:

Em suma, o princípio da soberania popular é a carta de navegação da cidadania rumo às conquistas democráticas, tanto para esta como para as futuras gerações. ${ }^{7}$

Para chegar à compreensão do que é a participação popular, temos de enxergá-la como um conceito histórico-social que necessita ser formatado de acordo com a época em que foi destacado e com os aspectos que marcaram a sociedade de então, como, por exemplo, quais lutas eram importantes e serviram de fundamento para a participação, quais conquistas foram assinaladas e que grupos efetivamente estiveram no "front".

Paulo Bonavides. Teoria constitucional da democracia participativa (Por um direito constitucional de luta e resistência, por uma nova hermenêutica, por uma repolitização da legitimidade) (São Paulo: Malheiros Editores, 2001)

6 Bonavides, Teoria constitucional da democracia participativa, 11.

7 Bonavides, Teoria constitucional da democracia participativa, 11. 
Um conceito para tentar compreender a participação popular pode ser o de vislumbrá-la como um processo experimentado por grupos sociais, no qual, reunindo força política e social, eles conquistem novos patamares de valores culturais, como bem expressa o trecho:

[...] um processo de vivência que imprime sentido e significado a um grupo ou movimento social, tornando-o protagonista de sua história, desenvolvendo uma consciência crítica desalienadora, agregando força sociopolítica a esse grupo ou ação coletiva, e gerando novos valores e uma cultura política nova. ${ }^{8}$

Na leitura de Carvalho, infere-se que há um processo de construção da participação popular evolutivo e contínuo, que nunca esteve ausente, em todos os momentos históricos houve grupos que defenderam minorias, direitos excluídos, citando mesmo alguns movimentos conhecidos das páginas dos livros de História do Brasil, como exemplos da constante presença da participação popular,

[...] desde as primeiras resistências indígenas e negras, como a Confederação dos Tamoios e os Quilombos, passando pelos chamados movimentos camponeses "messiânicos", como Canudos, pelas lutas abolicionistas, pela Independência, pelas revoltas urbanas contra a carestia, as mobilizações de inquilinos e tantas outras. ${ }^{9}$

Cada um dos momentos em que se demonstrou a intensidade de força presente nos movimentos populares de intervenção, nas decisões políticas e administrativas, representa um modelo de participação popular que oferece nuances próprias ao seu tempo. Sendo assim, elas não podem, por tais diferenças, ser minimizadas em seu valor intrínseco, que é o de oferecer espaço e voz ao cidadão.

Os caminhos que levam ao exercício da participação popular devem ser ampliados, evitando-se, desta maneira, a deturpação total do ideal democrático, como assinala, em sua Teoria da democracia participativa, Paulo Bonavides:

O povo que não é povo, a multidão que não é gente, a massa que se deixou domesticar, a classe média que já não tem influição no poder e jaz oprimida, o proletariado que perde cada vez mais a capacidade de luta e é perseguido

8 Maria da Glória Gohn. O protagonismo da sociedade civil: movimentos sociais, ONGs e redes solidárias (São Paulo: Cortez, 2008), 30.

9 Carvalho, Participação social no Brasil hoje. 
no salário configuram o retrato social da falsa república onde desde muito não sobrerrestam senão traços ou vestígios de cidadania. ${ }^{10}$

Outra fronteira a ser perseguida no caminho que leva à participação popular é a da liberdade de informação, que é garantida através de uma independência plena e total dos meios de comunicação. Somente pelo acesso a todos os fatos que permeiam as ações e decisões públicas, através de uma informação clara e ampla, comprometida tão somente com a verdade e alijada da influência do capital e do poder, é que se formarão os cidadãos com capacidade de participação ativa na vida pública.

Reportando esse desvio do aparelho ideológico da comunicação, Bonavides aponta com veemência a deturpação que pode nascer do mau uso do poder midiático:

A mídia escravizada ao capital deforma, entorpece e anula a livre vontade, o livre raciocínio, a livre consciência do ser político, rebaixado a cidadão nominal, a cidadão súdito, a cidadão vassalo — que enorme contradição isto representa! E assim as ditaduras constitucionais sobem ao poder e nele se conservam ostentando a imagem da pseudodemocracia e do pseudorregime representativo. ${ }^{11}$

Porém, quando mecanismos de ampliação dos canais de comunicação são implementados para que não se cinjam a pertencer somente às classes mais abastadas e à determinada facção política que representam, existe uma maior propensão a que haja informação precisa e universalizada sobre os acontecimentos relevantes, de modo que seja possível formar uma consciência cidadã capaz de impulsionar o indivíduo à participação nos processos decisórios e de construção social.

Em uma análise crítica da formação privatista do Estado brasileiro, Carvalho anota que a participação popular insere uma força contra hegemônica e consegue avançar em termos de garantias sociais:

A participação democrática nas decisões e ações que definem os destinos da sociedade brasileira tem sido duramente conquistada por esta mesma sociedade, de um Estado tradicionalmente privatista, que mantém relações simbióticas e corporativas com grupos privilegiados. ${ }^{12}$

Bonavides, Teoria constitucional da democracia participativa, 12.

Bonavides, Teoria constitucional da democracia participativa, 12.

Carvalho, Participação social no Brasil hoje. Contenido disponible en internet sin numero de pagina http:// polis.org.br/publicacoes/participacao-social-no-brasil-hoje/ (acceso 21 de noviembre de 2017). 
Ensinar o caminho da participação popular requer comprometimento de uma parte dos responsáveis pelas grandes forças de comunicação, porque, através da informação, o povo alienado e desinteressado na realidade política se converterá em um grupo coeso e organizado de cidadãos conscientes da sua força participativa e das suas responsabilidades públicas.

A introdução de disciplinas relacionadas ao conhecimento do direito nas escolas, como noções básicas de Direito Constitucional, enfatizando a conquista e a evolução dos Direitos Fundamentais, será um divisor de águas na formação cidadã das próximas gerações. O Projeto de Lei 70/2015, do Senador Romário, do estado do Rio de Janeiro, que incluiu a disciplina Direito Constitucional no currículo escolar do ensino básico, foi aprovado, no dia 6 de outubro de 2015, pela Comissão de Educação, Cultura e Esporte, no Senado, e seguiu para análise e aprovação da Câmara dos Deputados.

Esse exemplo de mudança legislativa para a educação cidadã revela uma justa intenção de iniciar um processo de conscientização da população a respeito dos direitos e deveres mínimos no que tange ao exercício de uma cidadania ativa, responsável e atuante.

Pode-se afirmar que esse caminho - o da educação — seja o mais longo para a cidadania, contudo, talvez seja também o mais determinante. Incutindo, desde a adolescência e juventude, valores e normas concernentes à participação popular como instrumento eficaz para implementação do princípio constitucional da cidadania.

O caminho da educação para a cidadania é inarredável em um Estado que se proponha a ser legitimamente democrático. A democracia participativa é o futuro ideal para esse modelo de governo, já que permite a discussão e o debate sobre as decisões a serem implantadas. É desse importante passo que passamos a falar.

\section{O caminho da educação cidadã}

Para tratar da educação, com o objetivo de alcançar a conscientização cidadã, é interessante ponderar sobre o papel da educação na formação da sociedade ativa. Como marcam Gorczevski e Martin, ${ }^{13}$ "todo indivíduo precisa da educação para

13 Clovis Gorczevski e Nuria Belloso Martín, Educar para os Direitos Humanos: considerações, obstáculos, propostas (São Paulo: Atlas, 2015), 16. 
sobreviver, mas a educação também é necessária para a sobrevivência da sociedade. É a educação que induz à ação, que permite ao indivíduo adaptar-se ao meio, a integrar-se na sociedade".

Já que a educação é um processo evolutivo do homem, através da qual este segue o curso do desenvolvimento criativo e reflexivo diante dos questionamentos e obstáculos surgidos no campo da sua existência.

No que tange à formação cidadã, com o conhecimento necessário para requerer respostas efetivas às suas necessidades, desde as mais básicas até as coletivas, os autores Gorczevski e Martín observam:

Uma limitação muito séria é a de não saber reclamar seus direitos e, mais grave ainda, de nem saber da existência desses direitos, situações das quais, frequentemente, se aproveita o Estado, denegando direitos, oferecendo-os como favor, ou pior, como moeda de troca. Dificilmente conseguiremos um perfil adequado de cidadão - independentemente da tradição filosófica que se deseje, liberal, comunitarista ou republicana — se o indivíduo não possui formação e instrução adequadas para elaborar seus próprios conceitos, para que forje suas próprias convicções, para que adquira responsabilidade cívica, para que seja capaz de resolver conflitos sem o uso da violência e tantas outras possibilidades às quais somente uma educação adequada abre as portas. ${ }^{14}$

Embora registrados e solenemente inscritos na Constituição brasileira de 1988, muitos dos instrumentos de participação popular previstos são pouco ou nunca empregados efetivamente. Podem ser citados o plesbicito, o referendo, a iniciativa popular de leis, a ação popular, o habeas corpus, o habeas data, o mandado de segurança, o mandado de injunção, além da previsão da gestão democrática em diversos instantes na Administração da res publica, como na previsão do artigo 29, inciso XII, o planejamento participativo mediante cooperação de associações representativas na ordem municipal, ou na previsão do artigo 114, inciso VI, sobre a participação quadripartite de governos, trabalhadores, empresários e aposentados na gestão administrativa da seguridade social e, mais adiante, no artigo 206, inciso VI, que trata da gestão democrática do ensino público.

14 Gorczevski e Martín, Educar para os Direitos Humanos, 26. 
Razões para tal circunstância podem ser elencadas buscando polos passivos de culpa na má vontade dos gestores, na morosidade do judiciário para fazer com que sejam cumpridos, através de decisões ao jurisdicionado, os direitos fundamentais inscritos na lei superior; todavia, o fator preponderante para a inobservância do direito à participação popular pode estar na desinformação do cidadão a respeito da existência de tal direito e sobre os instrumentos para sua efetivação.

Mamede ${ }^{15}$ em palavras linheiras, denuncia os porquês de não haver espaço para o exercício da cidadania no Brasil, nominando-os de obstáculos e especificando três:

[...] $1^{\circ}$ ) o sistema jurídico brasileiro não possui uma ampla definição de possibilidades para uma efetiva participação popular consciente; $2^{\circ}$ ) a postura excessivamente conservadora de parcelas do Judiciário, apegando-se a interpretações que limitam absurdamente o alcance dos dispositivos legais que permitiriam uma efetiva democratização do poder; por fim, $3^{\circ}$ ) uma profunda ignorância do Direito: a esmagadora maioria dos brasileiros não possui conhecimentos mínimos sobre quais são os seus direitos e como defendê-los.

Existem condições para o exercício da participação popular, dimensionadas por Santos Jr. ${ }^{16}$ em duas, que são: um ambiente democrático embasado na representação do poder e que garanta o direito ao exercício da cidadania política; e a existência de condições para o efetivo exercício dessa cidadania além de espaços públicos de interação entre os agentes públicos e a sociedade civil. Pode-se acrescentar, também, a exigência da educação para a cidadania.

Não haverá, ainda que essas duas primeiras condições citadas ou que os dois primeiros obstáculos sejam vencidos, o real envolvimento da população nos "negócios" públicos se não houver a formação através da educação. Continuará existindo essa grande massa populacional que se dobra e se deixa manipular por comandos momentâneos de pretensas lideranças, que nem sempre são motivadas por razões calcadas no interesse social.

Aprovado no Senado Federal, como já foi afirmado antes, o Projeto de Lei 70/2015, pode representar o exórdio da desmistificação do Direito Constitucional frente à população jovem de estudantes, que terão em seus currículos escolares noções dessa

15 Gladston Mamede, "Hipocrisia: o mito da cidadania no Brasil" em Revista de informação legislativa, n. 134 (abr./jun. 1997), 222. (abr./jun. 1997), 222.

16 Santos Jr. "Dilemas e desafios da governança democrática", 41-46. 
área do conhecimento jurídico e, assim, poderão conhecer o conteúdo mínimo da Constituição brasileira vigente, especialmente no que diz respeito aos Direitos Fundamentais.

Tal alteração legislativa não será suficiente para transformar a passividade dos cidadãos, instantaneamente, em modelo de cidadania ativa, com habitual pensamento de participação nas decisões e discussões a respeito da coisa pública; contudo, representa, definitivamente, um relevante passo no caminho para a educação cidadã.

Conhecer os Direitos Fundamentais e os instrumentos que garantem a sua efetivação é formar a base em que se assentarão os marcos da democracia participativa. Vê-se, nos ensinamentos de Leal, a relação intrínseca entre a promoção dos Direitos Fundamentais e a participação democrática:

O exercício da democracia depende da promoção antecedente dos Direitos Fundamentais que permitem aos cidadãos exercer com plenitude o seu direito de participação democrática. Mas a promoção desses direitos pela Administração Pública também exige que os atores sociais participem da deliberação, para formular e exigir a execução de políticas públicas adequadas à garantia do exercício desses direitos. ${ }^{17}$

Schmidt, ${ }^{18}$ sobre o cidadão estar a par do que lhe diz respeito no que tange às decisões administrativas públicas, diz ser de relevância:

[...] que conheça e entenda o que está previsto nas políticas que o afetam, quem as estabeleceu, de que modo foram estabelecidas, como estão sendo implementadas, quais são os interesses que estão em jogo, quais são as principais forças envolvidas, quais são os espaços de participação existentes, os possíveis aliados e os adversários, entre outros elementos.

Por outro lado, o fator educação deve ser considerado impulsionador do que se habituou chamar "empoderamento do cidadão", que é conquistado plenamente com o exercício da participação popular, pois nela os indivíduos "tornam-se protagonistas

Rogério Gesta Leal. Estado, Administração Pública e Sociedade: novos paradigmas (Porto Alegre: Livraria do Advogado, 2006), 77.

18 João Pedro Schmidt. "Para entender as políticas públicas: aspectos conceituais e metodológicos" em Direitos sociais e politicas públicas, tomo 8, org. J. R. Reis e R. G. Leal (Santa Cruz do Sul: Edunisc, 2008), 2308. 
da sua própria história, deixam de ser objetos das iniciativas de outros e tornam-se sujeitos de seu futuro."19

O caminho para a participação popular é a educação. É o disseminar da semente do conhecimento dos direitos e deveres concernentes à construção de uma vida plena em sociedade, por todos os rincões e recantos de cada país que se planeje e apresente como democrático, para que se formem cidadãos atinentes a suas responsabilidades públicas e sociais.

\section{Os cidadãos e seus limitados poderes: aporte para uma reflexão}

As tensões e preocupações grupais não deixam de resultar em um certo mal-estar. Por esse motivo, nem sempre é simplesmente afirmativa a discussão segundo direitos e garantias estabelecidas num texto jurídico positivo. Há, algumas vezes, resistências ao posicionamento de um Estado mais ou menos receptor dos poderes decisórios relativos à vida comunitária. Embora não seja tal abordagem o ponto central deste ensaio, vale traçar sucintos esboços críticos atrelados à complicada — porque conduz ao desejo de consenso fundado em pretensão relativa de aceitação majoritária das escolhas político-sociais - via democrática nos momentos transicionais, que são inevitáveis cruzamentos de ruptura.

No Brasil, as manifestações de 2015 por reformas políticas são o antítipo de uma reação policial cujos efeitos, mesmo que não absolutamente violentos (no sentido de massacre à multidão de opositores) para retenção dos ânimos revoltosos. $\mathrm{O}$ direito à expressão (movido por reunião e intervenção nos destinos pátrios) é natural quando se trata de reivindicação. ${ }^{20}$ A Constituição Federal de 1988 garante participação e liberdade de manifestação pública, ideia convertida em direito assegurado no rol do art. 5, legalmente superlativo no sentido de pertencer à fruição de garantias fundamentais, pois todos podem reunir-se pacificamente, sem armas, em locais abertos ao público, independentemente de autorização, desde que não frustrem outra reunião anteriormente convocada para o mesmo local, sendo apenas exigido prévio aviso à autoridade competente (Carta Política Brasileira, art. 5, XVI). Além disso, tratados internacionais e pactos compromissórios restringem a força

\footnotetext{
João Pedro Schmidt. "Exclusão, inclusão e capital social: o capital social nas ações de inclusão" em Direitos sociais e politicas públicas, tomo 6, org. J. R. Reis e R. G. Leal (Santa Cruz do Sul: Edunisc, 2006), 1774.

20 Fernando Antunes Netto. "A intervenção policial em manifestações públicas reivindicatórias". O Alferes, 71(27), (jul./dez. 2017), 13-31.
} 
vinculante dos órgãos controladores de beligerância interna. Os distúrbios podem ser contidos, mas, a sua organização (na medida do debate) não pode ter como desiderato a mera presença dos indivíduos, ela deve ser especialmente condicionada para que produza efeitos.

As manifestações em locais abertos são uma realidade desejável em nome da cidadania, mas não absoluta vantagem. O "ir e vir" (direito de locomoção) é um motivo para que o poder de polícia justifique mitigações nas manifestações organizadas (políticas ou não). O princípio da proporcionalidade é salutar. ${ }^{21}$ Sendo assim, o "meio mais eficiente" de conciliar direitos aparentemente antinômicos — porque são incompatíveis no plano inicial — é uma sugestão recomendável. ${ }^{22}$ Aplicar a lei — quando não for o caso de melhorá-la — impede arbitrariedades e significa maturidade no sistema jurídico. Aliás, o modelo de produção e aplicação normativo-positivista é suficientemente "neutro" ou ideologiza as massas convertendo-as nos tipos ideais de uma conformação passiva?

A pergunta sem resposta merece passar por reflexão, ou melhor, a indagação retórica merece passar por reflexão. As teorias convencionalmente aceitas - de fuga ou conformismo - são ingênuas porque ignoram a viabilidade de movimentos estratégicos capazes de orientar o "povo soberano" no viés das políticas públicas colaborativas. Metarregras para integração dos convívios, no sentido de "todos, nas suas limitações, participarem" é uma razoável perspectiva doutrinária e um sustentável meio de transformar novas gerações, contempladas na transformação dos hábitos sociais. Como pondera Manuel Asdrúbal Prieto Salas, o povo é titular da interpretação quando cumpre e traduz a Lei Superior Constitucional. ${ }^{23}$ Não seria coincidência que a Carta Brasileira defina o povo como fonte do poder e representado por seus eleitos legitimados (parágrafo único do artigo 1 — "Todo o poder emana

21 Nas palavras de Antunes Netto (A intervenção policial em manifestações públicas reivindicatórias, p. 21): "Para orientar as ações dos aplicadores do direito, está o princípio da proporcionalidade, que é regra fundamental a ser obedecida tanto pelos que exercem o poder quanto pelos que padecem o poder, afirma Müller (1978, p. 531 citado por Bonavides, 2008, p. 393)".

22 A polícia de Vancouver já procede com legitimidade nessa medida. A tropa de choque é substituída por cumprimentos e um polido estímulo à segurança ("estão todos bem?")

23 Uma vez que "La labor interpretativa del pueblo sobre los contenidos de la constitución debe desarrollarse a nivel político. El pueblo en este evento debe entenderse como una autoridad normativa de primer nivel que transmite su voluntad a una autoridad subordinada para que esta logre satisfacer los derechos consignados en la carta política. Esto conlleva, según los populares, que sería un error que el mismo creador de dicha normatividad no tuviera la facultad de interpretarla." (Salas, Manuel Asdrúbal Prieto. ¿Es posible la construcción de metarreglas para la regulación del control popular de interpretación constitucional? Soft Power, vol. 3, n. 1, (jan./jun. 2016), 221, grifos nossos) 
do povo, que o exerce por meio de representantes eleitos ou diretamente, nos termos desta Constituição.").

Ficamos, finalmente, sob os riscos e as esperanças. Nem modelos anômicos, tampouco sufragados no autoritarismo — a solução não se acha nesses extremos. $\mathrm{O}$ positivismo normativo não serve para, no plano dogmático, resolver e mediar conflitos transindividuais e difusos no meio social. Pensar em tal fator é inquietante, mas extremamente necessário para o planejamento de novos símbolos e possíveis inícios (que as nações buscam) democráticos que sejam úteis ao conceito universalizante de cidadania amplificada. ${ }^{24}$

Finalmente, os paradoxos continuarão a gerar controvérsias. O progresso e o desenvolvimento, que não são, necessariamente, sinônimos, orientarão a História para o lugar seguro do futuro sem, todavia, prescindirem da mão humana, capaz de "fazer o mundo" aprazível (para muitos) e aceitável (para o restante).

\section{Discussões e conclusões}

Conforme foi visto, a participação popular detém uma atribuição preponderante na continuidade e na confirmação do regime democrático. Passados tantos ciclos de retrocesso e evolução na história dos regimes de governo na América Latina, onde atualmente é necessário lutar, à custa de muito discurso e pouca ação, para manter as instáveis e engatinhantes democracias; é forçoso pensar e, principalmente, instrumentalizar e garantir a manutenção dos princípios derivados do regime das liberdades e igualdades.

Um instrumento eficaz e intrínseco à democracia é a participação popular. Não se pode conceber o governo de todos, pelo interesse de todos, se não estiverem todos articulados e se não forem todos ouvidos para que, no mínimo, tenham a possibilidade de opinar nos momentos de decisão mais relevantes.

24 "En efecto, si los contrastes reales sobre los valores constitucionales no emergen de la relevancia del principio de universalización sino de los niveles concretos de conflictualidad, la emersión del conflicto no siempre se puede contener dentro de una racionalidad argumentativa, exigiendo formas de renegociación política, procesos de subjetivación, que renueven en su interior la politicidad del derecho, la naturaleza 'estratégica' de la mediación jurídica sin pretender que la racionalidad argumentativa sea capaz siempre de absorber el conflicto ético político que se origina del pluralismo moral." (Giordano, Valeria. "Pluralismo de los valores y neutralización jurídica”. Soft Power, vol. 1, n. 2, (jul./dez. 2014), 140, citando L. Bazzicalupo). 
E não há que pensar a participação popular somente para o exercício do voto, em escolhas de representantes ou em opiniões decisórias nas situações de referendos e plebiscitos. Essa participação deve ser concebida de forma abrangente, englobando todas as formas previstas pela Constituição vigente, inclusive as que ainda não tenham sido assimiladas pelo povo, em parte, por sua desinformação a respeito delas.

Conquistar a efetividade da participação popular representa a garantia da democracia, na medida em que esta necessita daquela para manter-se sã; a democracia tem na participação popular um suprimento vital, poderia ser dito, em comparação figurativa, que a participação popular é o oxigênio que mantém a democracia viva.

Trilhar os caminhos que levam à plena participação democrática deve ser o objetivo de todas as nações que desejam se distanciar dos antigos regimes autoritários. A educação dos seus cidadãos para a participação popular é um caminho certo para alcançar tal desiderato. Um corpo de cidadãos ativos e conscientes de seus direitos e responsabilidades, frente ao que é comum a todos, será um elemento diferenciador na sustentação da democracia.

A democracia é uma conquista, é um direito fundamental, nas lições de Bonavides. Não pode ser esquecida ou renegada à função simbólica, sob pena de, como qualquer direito, cair em desuso. Uma democracia em desuso, socialmente ineficaz, abre espaço aos seus piores antagonistas, que são os modelos autoritários de regimes de governo. Uma democracia da qual não se exaure as amplas possibilidades que comporta, finda em transformar-se num modelo tacanho, apático e frágil, passível de ser destruído ou desmazelado por qualquer brisa de autoritarismo.

Uma democracia inteira e forte é construída pelas mãos de todos, mais precisamente pelas vozes de todos, não em uníssono, mas em diversos tons, formando uma verdadeira orquestra de opiniões e ideias que, mesmo que não sejam aceitas em sua totalidade, terão sido ponderadas e analisadas na intenção de buscar o bem comum, que é o modo mais favorável e justo para cada situação.

Educar para esse momento ideal de construção democrática é um dos primeiros passos a serem dados. Criar no ser em formação — em idade escolar — a consciência de que se for um cidadão atuante e ativo ele estará assegurando uma vida mais digna para si e para todos, certamente, fará diferença no futuro desse indivíduo. Parece ideal, irreal e utópico em demasia, mas de que é feita a realidade se não de fatos antes inimagináveis? 


\section{REFERÊNCIAS}

Antunes Netto, Fernando. "A intervenção policial em manifestações públicas reivindicatórias". O Alferes, 71(27), (jul./dez. 2017): 13-31.

Baquero, Marcello. "Subsídios para a compreensão da cultura político-eleitoral da democracia brasileira". Política e Sociedade, n. 10, n.10 (abril 2007): 25-51, https://periodicos.ufsc. br/index.php/politica/article/view file/1683/1427 (acceso 21 de noviembre de 2017).

Bonavides, Paulo. Do estado liberal ao estado social. São Paulo: Malheiros, 2013.

Bonavides, Paulo. Teoria constitucional da democracia participativa (Por um direito constitucional de luta e resistência, por uma nova hermenêutica, por uma repolitização da legitimidade). São Paulo: Malheiros Editores, 2001.

Carvalho, Maria do Carmo A. A. Participação social no Brasil hoje. São Paulo: Instituto Pólis, 1998. http://polis.org.br/publicacoes/participacao-social-no-brasil-hoje/ (acceso 21 de noviembre de 2017).

Giordano, Valeria. "Pluralismo de los valores y neutralización jurídica". Soft Power, vol. 1, n. 2, (jul./dez. 2014): 125-146.

Gohn, Maria da Glória. O protagonismo da sociedade civil: movimentos sociais, ONGs e redes solidárias. São Paulo: Cortez, 2008.

Gorczevski, Clovis e Martín, Nuria Belloso. Educar para os direitos humanos: considerações, obstáculos, propostas. São Paulo: Atlas, 2015.

Leal, Rogério Gesta. Teoria do Estado. Cidadania e poder político na modernidade. Porto Alegre: Livraria do Advogado, 2001.

Leal, Rogério Gesta. Estado, Administração Pública e Sociedade: novos paradigmas. Porto Alegre: Livraria do Advogado, 2006.

Luchesi, Eduardo. "Participação política para humanização do processo legislativo e garantia da máxima efetivação dos direitos humanos". Constitucionalismo contemporâneo: desafios e perspectivas. Organizado por Clovis Gorczevski e Mônia Clarissa Hennig Leal. Curitiba: Multideia, 2012.

Mamede, Gladston. "Hipocrisia: o mito da cidadania no Brasil". Revista de informação legislativa. Brasília, n. 134 (abr./jun. 1997)

Salas, Manuel Asdrúbal Prieto. “¿Es posible la construcción de metarreglas para la regulación del control popular de interpretación constitucional?". Soft Power, vol. 3, n. 1, (jan./ jun. 2016): 219-228.

Schmidt, João Pedro. Juventude e política nos anos 1990: um estudo de socialização política no Brasil. Tese de doutorado. Universidade Federal do Rio Grande do Sul, 2000. http:// repositorio.unisc.br/jspui/ (acceso 21 de noviembre de 2017). 
Schmidt, João Pedro. "Exclusão, inclusão e capital social: o capital social nas ações de inclusão". Direitos sociais e políticas públicas, tomo 6. Organizado por J. R. Reis e R. G. Leal. Santa Cruz do Sul: Edunisc, 2006.

Schmidt, João Pedro. "Para entender as políticas públicas: aspectos conceituais e metodológicos". Direitos sociais e políticas públicas, tomo 8. Organizado por J. R. Reis e R. G. Leal. Santa Cruz do Sul: Edunisc, 2008.

Santos Jr., O. A. "Dilemas e desafios da governança democrática". Os sentidos da democracia e participação. Organizado por Ana Claudia Chaves Teixeira. São Paulo: Instituto Pólis, 2005. 